\title{
Editorial: On the ethical maximisation of research publications
}

\section{New appointments}

I am pleased to report several positive developments during 2009. Late in the summer, Jim Ogg was appointed as the second Associate Editor. Jim's first degree was in social anthropology. After four years as a social worker, he became a researcher, briefly at the Centre for Policy for Ageing, and subsequently at the University of Keele and The Young Foundation in London. He has conducted both ethnographic studies and multivariate analyses of French and European datasets, and collaborated with several leading European gerontologists. Jim is currently Senior Researcher at the Direction des Recherches sur le Vieillissement at the Caisse Nationale d'Assurance Vieillesse in Paris, the research arm of the French national bureau of old-age social security. Jim joins Mima Cattan who was appointed as the first Associate Editor in 2006 and has recently taken up a Chair in Public Health at the University of Northumbria in Newcastle-upon-Tyne. Jim and Mima bring much needed additional capacity to the editorial team. We have high hopes of Jim's connections into francophone and European social gerontology and policy debates, just as Mima's experience and networks in health promotion and occupational therapy have been invigorating.

Another change in the editorial team took place in December 2009 when Caroline Holland and Josie Tetley succeeded Joanna Bornat and Julia Johnson as Review Editors. All four work at the Open University, so Stella Allison helpfully will continue as the Review Editors' Assistant. Josie was a nurse for over 26 years, specialising in research, practice and education in the field of ageing, health and wellbeing. Her research has focused on lay involvement and participation in research, and she has strong links with colleagues from physiotherapy, occupational therapy, social work, housing, mental health and creative therapy services. Caroline has been a full-time researcher in ageing for over I5 years, focussing on social housing and community work. She is particularly interested in cultural, social and policy aspects of homes, neighbourhoods and civic society; and 
the use of communications and assistive technologies by older people. Josie and Caroline have many innovative ideas for developing the review section. Before moving on, I express my deep thanks to Joanna and Julia for their reliable and hugely effective stewardship of the Review Section, particularly in adapting to eight issues each year. They have done extremely well in maintaining the flow of increasingly substantial reviews at a time when many academic departments do not encourage staff to spend time in this way.

\section{Submitted papers}

The demand for space in the journal and the quality of the accepted papers continue to rise. The growth in submissions began in 1998, when 65 papers were received compared to 57 in I997. Every year since submissions have increased, near exponentially, to around 220 in 2009, roughly one-quarter more than in 2008. The ratio of published to submitted papers has not worsened commensurately, however, for two reasons. First, Cambridge University Press has readily agreed to the expansion of the journal (most recently from six to eight issues in 2008, and by a further 128 pages in both 2009 and 2010, to a total of I, 472 for volume 30). Second, the mean page length of the main papers has steadily decreased, from 22.3 in 200 I to I8.9 in 2009. The proportion of submitted papers that are eventually published (most after revision) was around 0.45 in $200 \mathrm{I}$ and is now around 0.35 .

It is not the number but the fresh topics and approaches of the papers and their widening provenance that most pleases. The share of the published papers by non-UK first authors increased from 33 per cent in I998 to 77 per cent in 2008, and receded to $7 \mathrm{I}$ per cent in 2009. Recent years have seen more contributions than for some time from anthropologists and psychologists and, a welcome change, more than occasional submissions from economists. The growth has not been in inappropriate or second-rate papers; indeed, my firm view is that over the last five years average quality has increased. We receive more papers based on large, rigorous national and special-topic databases, more papers from multi-disciplinary research teams, and more reports from concerted and well-designed in-depth studies. Over the last five years, systematic reviews and meta-analyses have become well established in gerontology research. When substantial, they raise distinctive problems for authors and editors about which details of their successive steps it is necessary and useful to report, a matter to which I will return. 


\section{Special issues}

During 2009, there were lengthy discussions at the Editorial Board and repeated inquiries from the International Advisors about our 'policy on special issues', and it may be that readers share the interest. The main elements are that the Board welcomes proposals for special issues but no more than two will be approved for any one volume (of eight issues). Proposals must include the academic case for the collection and substantial abstracts for each of the intended papers. The proposals are evaluated by the Editorial Board and the International Advisors, and high standards are applied regarding originality, the coherence of the collection and the importance of the topic. Among procedural details, the approval of a proposal does not guarantee the publication of the individual contributions, which can be peer-reviewed in the normal way, with the final decision resting with the Editor-in-Chief. Commissioning and shepherding a truly original and co-ordinated set of papers through to publication is not a light task.

Two distinctive special issues of considerable merit were published in volume 29. The August issue had six papers on Discourse, Identity and Change in Mid-to-late Life commissioned by Justine Coupland, and the November issue had five papers on Childlessness and Inter-generational Transfers commissioned by Martin Kohli and Marco Albertini. Both break new ground and demonstrate that the collocation of original papers on a single topic but with different emphases and perspectives can make an exceptional contribution. While keenly aware that special issues delay the publication of submitted papers, over the years their frequency has not been high: there were none in 2008 or 2007, two in 2006, and none in 2004. Many inquiries and outline plans are received, but few fully developed proposals arrive and proceed to evaluation.

\section{Publication ethics}

Many readers will be aware of the increasing regulation of authors and published papers by peer-reviewed journals in the clinical and natural sciences. A speaker at the Royal Society of Medicine in London is asked to declare funding and conflicts of interest. As the declaration form explains, 'the RSM aims to ensure balance, objectivity and high scientific standards in all its academic activities. All speakers and chairmen of meetings are expected to disclose to the audience any financial or other relationship that represents a competing interest. This may include research grants or other financial support, employment in any capacity by a company, 
including the role of consultant or advisor, or any share holding in a company.' The intention of the disclosure is 'to provide the audience with information on which they can base their own judgements. It is up to the audience to decide whether or not the declared interests of a speaker may influence the content and emphasis of their presentation.' The aims are laudable and shared by the humanities and social sciences, but if these principles are applied to peer-reviewed publication in our fields, the procedure can become intricate and onerous because questions of originality and authorship come to the fore (rather than of scientific fraud or deception).

The question is whether we should follow the monitoring and regulatory practices now common in the physical, biological and medical sciences. It is raised because issues around originality and the attribution of authorship have surfaced recently among the submissions to this journal. During 2009, for example, the following departures from best practice occurred. We published a paper from a large team that is very similar to a paper previously published in another continent. Two papers submitted in close succession from different members of the same research team did not cross reference and made contradictory recommendations. Submissions based on systematic reviews were received that were less than candid or clear about what had already been published or the particular, additional contribution of the paper. One author gave an affiliation that no longer applied and that had not been approved, and had not notified former colleagues about the submission. Such lapses are exceptional; the common and age-old problem is redundant or replicated publication, and not only for Ageing \& Society: a survey of 23I international journal editors' views on publication ethics found that redundant publication was 'the issue of greatest concern' (Wager et al. 2009: 348).

I offer some preliminary comments on this and other aspects of publication practice, partly drawing from the Guidelines on Good Publication Practice produced by the Committee on Publication Ethics (COPE) (I999). COPE began as an informal support group among British Medical fournal editors, offers advice for editors including a Code of Conduct and Best Practice Guidelines (see http://publicationethics.org/), and aims to find practical ways of spreading good practice. The Guidelines define redundant publication as occurring 'when two or more papers, without full cross reference, share the same hypothesis, data, discussion points, or conclusions'. They then set out four 'action' or good practice points:

I. Published studies do not need to be repeated unless further confirmation is required. 
2. Previous publication of an abstract during the proceedings of meetings does not preclude subsequent submission for publication, but full disclosure should be made at the time of submission.

3. Re-publication of a paper in another language is acceptable, provided that there is full and prominent disclosure of its original source at the time of submission.

4. At the time of submission, authors should disclose details of related papers, even if in a different language, and similar papers in press.

I believe these guidelines fully apply to Ageing $E$ Society. The first is couched in editors' shoptalk and a little obscure, but with the fourth guideline expresses the fundamental principle that it is the author's responsibility not only to be explicit about the originality of the submitted paper but also to set out clearly how the paper's contribution relates to others from the same data, study or team. The COPE Guidelines have sections on: Study design and ethical approval, Data analysis, Authorship, Conflicts of interest, Peer review, Redundant publication, Plagiarism, Duties of editors, Media relations, Advertising, and Dealing with misconduct. A few points are particular to clinical studies, but most are widely applicable and great good sense. They are recommended to all authors in our disciplines, not least for the nuggets of practical wisdom, as with 'misconduct is intention to cause others to regard as true that which is not true'. My remaining comments are confined to the guidelines on authorship, which begin with: 'There is no universally agreed definition of authorship, although attempts have been made. As a minimum, authors should take responsibility for a particular section of the study.' Four action points then follow:

I. The award of authorship should balance intellectual contributions to the conception, design, analysis and writing of the study against the collection of data and other routine work. If there is no task that can reasonably be attributed to a particular individual, then that individual should not be credited with authorship.

2. To avoid disputes over attribution of academic credit, it is helpful to decide early on in the planning of a research project who will be credited as authors, as contributors, and who will be acknowledged.

3. All authors must take public responsibility for the content of their paper. The multidisciplinary nature of much research can make this difficult, but this can be resolved by the disclosure of individual contributions.

4. Careful reading of the target journal's 'Advice to Authors' is advised, in the light of current uncertainties. 
These guidelines are commended and should be followed by all who submit to Ageing \& Society but are perhaps too limited and terse. I believe that there are detailed differences in best practice in the attribution of authorship as between clinical research papers and social studies or humanities writing (with health-services research teams unsure which norms to follow). One is in the distinction between legitimate authors, defined appropriately as those who have made an intellectual contribution, from others who have performed 'the collection of data and other routine work'. In the social sciences, not only in anthropology, different differentiations may apply. I think of in-depth interviewers, particularly those who engage with 'difficult to reach' subjects, whether very disadvantaged, reluctant or suspicious participants, or those with major personal problems, or comparatively inarticulate people whose opinions and attitudes are sought, or those of minority ethnicities or cultures. As recent papers submitted to this journal have declared, many interviewers and focusgroup facilitators make important and even critical contributions to recruitment procedures, to the design and implementation of effective and useful data collection, and to the interpretation of the data and findings. The spreading practice of 'validating' interpretations by feedback to the participants and the data collectors reinforces the point.

The second point of difference relates to the third guideline, 'all authors must take public responsibility for the content of their paper'. I have observed that clinical researchers accept this precept but treat it as a technicality. By contrast, the custom in social studies and the humanities has been that all named authors see and approve the submitted version of a paper, but now this practice is not always observed. New modes of 'research production', particularly the contrived formation of multidisciplinary and multi-centre teams that funding agencies now encourage (as distinct from teams that grow spontaneously and have protracted engagement with a shared interest), may be making it difficult for each team member to read and approve every paper that a large, geographicallydispersed group produces. Nonetheless, I believe the custom should be scrupulously followed for all named authors on a paper. There are good practical reasons: if an author does not have a close knowledge of a paper on which they are named, when submitting other papers they are more likely to fail to give a full and accurate account of what has been published before, and will be less able to specify accurately the submission's original contribution.

Many large surveys, other primary studies and systematic reviews can and should support more than one peer-reviewed paper. When a large investment has been made, it is right that the returns to understanding are maximised, but neither health-service researchers nor social scientists are 
consistently following best practice publication rules. Timeless requirements apply: every paper should make an original contribution and build from a foundation of current theoretical and empirical understanding, as conventionally accomplished through a literature review, but new modes of research production have magnified the technical and ethical difficulties around what should be reported in each paper. The problems are confounded with secondary inquiries or analyses that use a sub-sample from a larger study, as when an in-depth qualitative investigation is added to a structured survey. The technical challenge is to report the methodology, sampling procedures and design of both the primary and secondary studies without extensive replication but sufficiently for the reader to be able to evaluate the authority of the findings without reference to other papers. These issues require and will receive wide and full debate. If eventually new declaration forms or procedures are introduced, the demands on authors will be kept to the minimum required.

\section{Thirtieth volume celebrations}

The 3 oth volume of the journal will be celebrated in several ways. I will give a reflective lecture on 'Ageing and modernisation' at the annual meeting of the British Society of Gerontology during 6-8 July at Brunel University in west London, and there are plans for a symposium on 'gerontology publishing' with the journal's past and present editors. Aside from conference events, several accomplished authors have agreed to prepare papers that reflect on development and change in gerontology understanding over the last 30 years. One never knows what will arrive but I am sure there will be gems.

\section{References}

Committee on Publication Ethics (COPE) 1999. Guidelines on Good Publication Practice. COPE, London. Available online at http://publicationethics.org/static/1999/ I999pdfi3.pdf [Accessed i November 2009].

Wager, E., Fiack, S., Graf, C., Robinson, A. and Rowlands, I. 2009. Science journal editors' views on publication ethics: results of an international survey. Fournal of Medical Ethics, 35, 348-53. Published electronically at doi:ı.1136/jme.2008.028324.

\section{TONY WARNES}

